University of Wollongong

Research Online

Faculty of Engineering and Information

Faculty of Engineering and Information

Sciences - Papers: Part A

Sciences

$1-1-2016$

Deadband control of doubly-fed induction generator around synchronous speed

Yingjie Tan

University of Wollongong, yt816@uowmail.edu.au

Kashem M. Muttaqi

University of Wollongong, kashem@uow.edu.au

Lasantha G. Meegahapola

University of Wollongong, lasantha.meegahapola@rmit.edu.au

Phil Ciufo

University of Wollongong, ciufo@uow.edu.au

Follow this and additional works at: https://ro.uow.edu.au/eispapers

Part of the Engineering Commons, and the Science and Technology Studies Commons

Research Online is the open access institutional repository for the University of Wollongong. For further information contact the UOW Library: research-pubs@uow.edu.au 


\title{
Deadband control of doubly-fed induction generator around synchronous speed
}

\author{
Abstract \\ Semiconductor devices in power electronic converters of the doubly-fed induction generator (DFIG) are \\ susceptible to significant junction temperature variations when operating around synchronous speed, \\ thereby reducing the lifetime of the converters. This is due to the fact that the frequency of the rotor \\ current in a DFIG is determined by the stator flux frequency and rotor speed, and hence will lead to low \\ rotor current frequency when operating closer to the synchronous speed, and ultimately result in \\ significant thermal stress on semiconductor devices. In this paper, a multimode operation control strategy \\ is proposed for the DFIG to prevent operating around the synchronous speed (within a predefined \\ deadband); thus, the proposed control strategy can avoid the thermal stress problem. The proposed \\ strategy engages the existing crowbar scheme for DFIG-based wind energy conversion system to \\ intentionally alter the operating mode of the generator between DFIG and induction generator (IG). \\ Smooth transition between the two operating modes can be achieved with the supplementary control \\ strategies. Unity power factor can also be maintained in both operating modes by using the grid side \\ converter as a static synchronous compensator (STATCOM) to fulfill the reactive power requirement of \\ the DFIG in IG mode.

\section{Disciplines} \\ Engineering | Science and Technology Studies \\ Publication Details \\ Y. Tan, K. M. Muttaqi, L. Meegahapola \& P. Ciufo, "Deadband control of doubly-fed induction generator \\ around synchronous speed," IEEE Transactions on Energy Conversion, vol. 31, (4) pp. 1610-1621, 2016.
}




\title{
Deadband Control of Doubly-Fed Induction Generator around Synchronous Speed
}

\author{
Yingjie Tan, Student Member, IEEE, Kashem M. Muttaqi, Senior Member, IEEE, \\ Lasantha Meegahapola, Member, IEEE, and Phil Ciufo, Senior Member, IEEE
}

\begin{abstract}
Semiconductor devices in power electronic converters of the doubly-fed induction generator (DFIG) are susceptible to significant junction temperature variations when operating around synchronous speed, thereby reducing the lifetime of the converters. This is due to the fact that the frequency of the rotor current in a DFIG is determined by the stator flux frequency and rotor speed, and hence will lead to low rotor current frequency when operating closer to the synchronous speed, and ultimately result in significant thermal stress on semiconductor devices. In this paper, a multimode operation control strategy is proposed for the DFIG to prevent operating around the synchronous speed (within a predefined deadband), thus the proposed control strategy can avoid the thermal stress problem. The proposed strategy engages the existing crowbar scheme for DFIG based WECS to intentionally alter the operating mode of the generator between DFIG and induction generator (IG). Smooth transition between the two operating modes can be achieved with the supplementary control strategies. Unity power factor can also be maintained in both operating modes by using the grid side converter as a static synchronous compensator (STATCOM) to fulfil the reactive power requirement of the DFIG in IG mode.
\end{abstract}

Index Terms-Crowbar, doubly-fed induction generator (DFIG), multimode operation, synchronous speed, wind power, thermal analysis.

\section{INTRODUCTION}

$\mathrm{D}$ OUBLY-fed induction generator (DFIG) based wind energy conversion systems (WECSs) are widely used around the world for the wind energy harvesting. The reliability of the WECS is an important consideration which ensures a high return on the investment. Surveys carried out in [1, 2] showed that the semiconductor devices are the most vulnerable components in WECSs.

Power converters of the WECS are designed to be in service for 20-25 years, and thermal performance is closely related to the reliability of semiconductor devices in the converters [3]. Packaging-related failure mechanisms of semiconductor devices, such as bond wire lift-off and solder fatigue, are affected by junction temperature as well as temperature fluctuations in power cycling of the semiconductor devices [4]. The lifetime (or the number of cycles to failure) of switching devices is proportionally decreased with an increase in the amplitude

Y. Tan, K. M. Muttaqi and P. Ciufo are with the Australian Power Quality and Reliability Centre, School of Electrical, Computer, and Telecommunications Engineering, University of Wollongong, NSW 2522, Australia (e-mail: yt816@uowmail.edu.au; kashem@uow.edu.au; ciufo@uow.edu.au).

L. Meegahapola is with the School of Electrical and Computer Engineering, Royal Melbourne Institute of Technology, Melbourne, Vic. 3000, Australia (e-mail: lasantha.meegahapola@rmit.edu.au). of junction temperature fluctuation [5]. As stated in [5], the minimum operating frequency is a critical parameter of a power semiconductor device apart from overcurrent, and the designer has to take the pulsing of junction temperature into consideration when the converter operating frequency is low, since the junction temperature has a higher variation at a lower operating frequency and the maximum junction temperature is likely to be exceeded.

Conventionally, power electronic devices in the utility power industry have low temperature swings [1], but the application of wind power brings large transients and thermal cycling issues. For example, when the rotor speed approaches synchronous speed in a DFIG, the rotor current frequency becomes low as the rotor current frequency equals to the slip frequency. Hence, higher temperature swing and shorter life span of power switches in the rotor side converter (RSC) are resulted. In [6], the variation of the semiconductor junction temperature was shown to be reaching its maximum around the synchronous speed when the slip is low and the period of thermal cycle is long. The authors in [7] also suggested that the maximum junction temperature in the IGBTs of the RSC are likely to be exceeded around synchronous speed. A power cycling capability estimation method was proposed for the DFIG in [8] and the negative effect of low slip frequency operation on power cycle capability of a DFIG power converter was studied. Authors in [9] concluded that the thermal performance of semiconductors in an RSC becomes crucial around the synchronous operating point. Therefore, semiconductor devices in the RSC are significantly stressed around synchronous speed, and it is important to investigate and propose strategies to overcome the thermal stress issue.

\section{LIMITATIONS IN EXISTING CONTROL STRATEGIES}

Limiting the junction temperature of the semiconductor devices within rated limits is strictly required for maintaining the longevity of the converter. By limiting the power transfer of the converter can regulate the junction temperature [10], for example, rotor current is limited to avoid further temperature increases when the rotor winding temperature increases by $86 \%$ around synchronous speed [11], but the effectiveness of intended control strategy will be affected. A converter of higher rating and a heat sink of lower maximum temperature can be a solution, but additional investment and larger space is required. Authors in [12] proposed a different converter topology to decrease the power loss and thus reduce the risk of overheating, which may not be the preferable solution for 
WECS manufacturers due to high cost and space constraints [7]. The authors of [7] suggested the use of a discontinuous PWM technique to reduce power loss of the DFIG and thus the maximum junction temperature, enabling the generator to operate within the entire speed range. In [13], the authors found that the mean time to failure (MTTF) of the IGBTs in a variable speed drive system reduces dramatically at higher junction temperature variation, and a switching frequency reduction strategy was proposed in order to reduce the power loss under low output frequency operation, thus improving MTTF. With these sophisticated PWM techniques, the thermal problem of synchronous operation can be reduced, but the resulting harmonics problem can be difficult to address. For example, the variation in switching frequency may introduce difficulty in harmonics filtering, and advanced harmonics filtering techniques and devices are required [10]. Furthermore, there is a common limitation in existing control strategies, since the solutions are mainly capable of reducing the mean junction temperature but have limited impact on reducing the temperature swings which is mainly affected by the fundamental output frequency. As mentioned in [7, 11], another solution is to avoid synchronous operation in practical applications. In [14], an unstable section replaces the typical MPPT curve around synchronous speed. Consequently, the rotor speed slides through the unstable region when the rotor speed approaches the predefined speed range. However, mechanical torque stress caused by the fast torque change around synchronous speed brings burden on the drive-train and increases wear and tear of the drive-train. The gearbox and drive-train have the longest downtime per failure, and energy production can be significantly affected under drive-train failure [2].

In this paper, a multimode operation strategy is proposed to prevent the DFIG operating within a predesigned range around the synchronous speed. Hence, the large junction temperature variation can be avoided. The strategy utilizes the existing crowbar protection scheme of a DFIG in order to operate it as an induction generator (IG) when it approaches a predefined speed range close to synchronous speed. Supplementary control strategies are proposed to achieve a smooth transition between the DFIG mode and the IG mode. The back-to-back converter scheme of the DFIG is used as a static-synchronous compensator (STATCOM) to satisfy the reactive power requirement of the generator in IG mode. With the proposed strategy, neither additional facilities nor modifications to the current system configuration are required. Therefore, the thermal issue can be solved without derating the current performance of the DFIG and violating the grid-code standards. Power loss model and thermal network for the RSC are established to verify the effectiveness of the proposed strategy.

\section{OPERATION OF WIND ENERGY CONVERSION SYSTEM}

\section{A. Low Slip Frequency Problem of DFIG}

A DFIG based WECS is mainly composed of a wind turbine, drive-train, wound rotor induction machine (WRIM) and back-to-back voltage source converter scheme as illustrated in Fig. 1. The voltages and currents of variable frequencies sup- plied by the RSC enable the wind turbine to operate at variable speeds while keeping WECS synchronized with the grid. The control mechanisms for RSC and the grid side converter (GSC) are well described in the published literature [15], for brevity, will not be described in this paper.

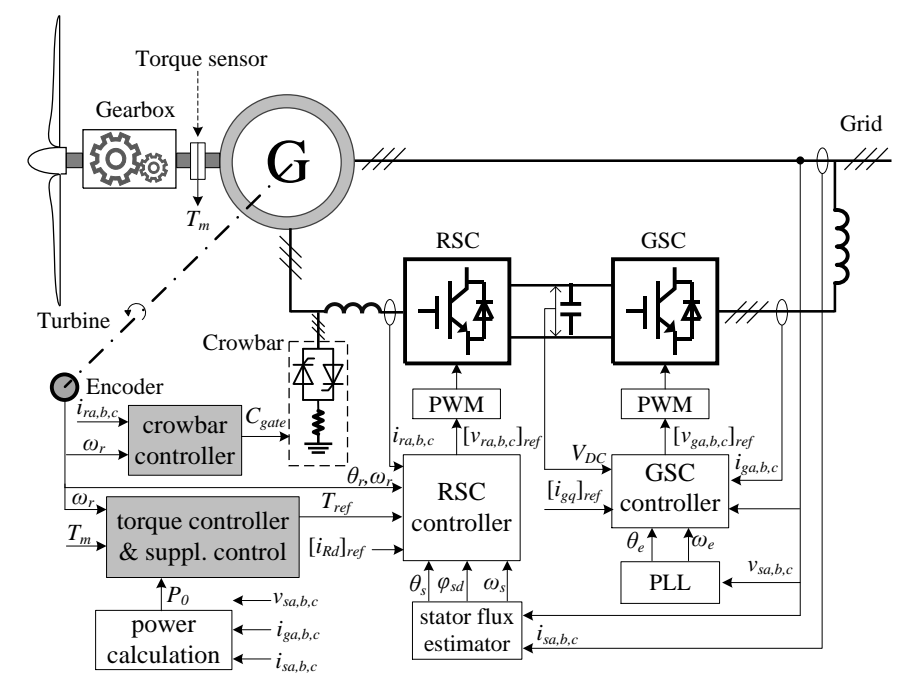

Fig. 1 Control diagram of the DFIG based WECS.

The angular frequency of rotor voltages and currents $(\omega)$ in a doubly-fed induction machine is determined by the angular frequency of stator flux or the angular frequency of stator voltages and currents $\left(\omega_{\mathrm{s}}\right)$ and the rotor rotational speed $\left(\omega_{\mathrm{r}}\right)$ [16] (i.e. $\omega=s \omega_{\mathrm{s}}$ with the $s$ being the slip). Therefore, the angular frequency of the rotor current becomes very small when the slip approaches zero (i.e. the rotor speed approaches the synchronous speed). For the DFIG used in this paper, the performance of the generator around synchronous speed is presented in Fig. 2. Since lower frequency causes much longer temperature rises and falls, larger peak to peak swings will occur. For example, an enhanced air cooling system (with an air-flow of $120 \mathrm{~m}^{3} / \mathrm{h}$ and a heat sink to ambient thermal resistance, $R t h_{\mathrm{h}-\mathrm{a}}$, of $0.093 \mathrm{~K} / \mathrm{W}$ [5]) is applied to the DFIG power converter in this paper, the resulting variation in IGBT junction temperature is shown by the orange curve in Fig. 2(c). The variation reaches its maximum value (around $100{ }^{\circ} \mathrm{C}$ ) when the rotor speed is exactly at synchronous speed and stays at the synchronous speed (which is unlikely to happen), because RSC supplies direct current and IGBTs are constantly turned on or off. The lifetime of power semiconductors decreases with an increase in the amplitude of junction temperature fluctuation. With a more sophisticated liquid cooling system (e.g. flow rate $=8 \mathrm{~L} / \mathrm{min}$, water/glycol ratio 50\%:50\% [17]), the heat sink to ambient thermal resistance reduces to $0.0092 \mathrm{~K} / \mathrm{W}$. The mean junction temperature is reduced and the variation in junction temperature is narrowed as shown by the blue curve in Fig. 2-(c). However, the sophisticated cooling system demands higher investment and, operation and maintenance costs also increase. Therefore, the authors propose a deadband control for the DFIG around synchronous speed to reduce junction temperature swings without upgrading the cooling system. 

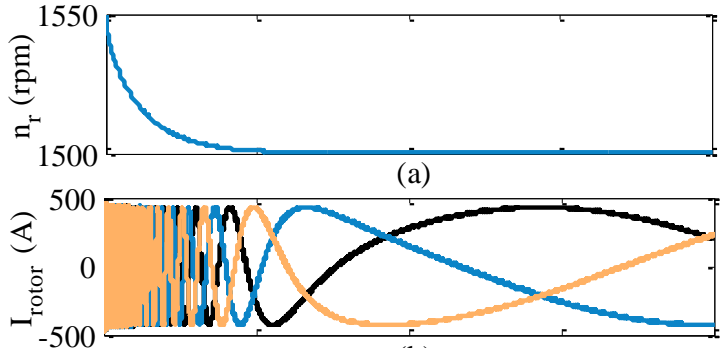

(b)

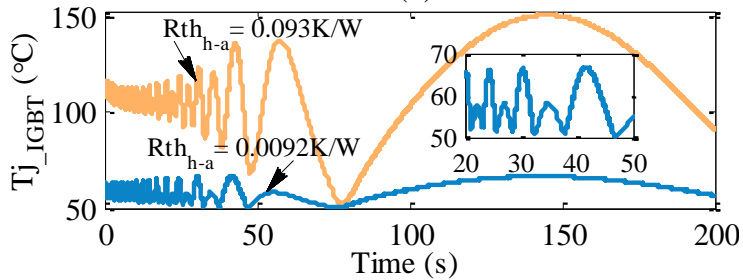

(c)

Fig. 2 Operation of a DFIG based WECS around synchronous speed. (a) Rotor speed. (b) Rotor three-phase currents. (c) Junction temperature of an IGBT in RSC.

\section{B. Proposed Multi-Mode Operation}

Sudden grid voltage disturbances, such as voltage dips, can induce a large inrush current in rotor windings and could potentially damage the DFIG rotor windings and semiconductor devices of the RSC. A crowbar system, as shown in Fig. 3, is widely being used to protect the DFIG based WECS during grid faults and to improve the low-voltage-ride-through (LVRT) capability. The crowbar consists of resistors and semiconductor switches. When the switches are turned on, the resistors are connected in series with the rotor windings and the IGBTs of the RSC are blocked. Consequently, the generator operates similar to an IG.

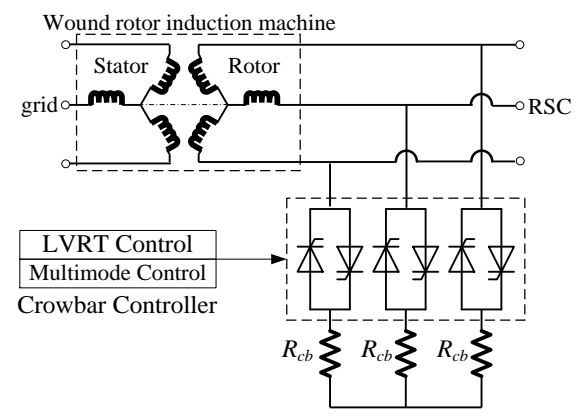

Fig. 3 Schematic diagram of a crowbar for a DFIG based WECS.

In this paper, the crowbar protection scheme is used to facilitate the proposed multi-mode operation (i.e. DFIG mode and IG mode as explained below). The multi-mode operation prevents the rotor speed of the DFIG from being within a particular range around synchronous speed. That is, a predesigned deadband $\left[\omega_{\mathrm{s}}-\varepsilon, \omega_{\mathrm{s}}+\varepsilon\right]$ is set for DFIG operation. The tolerance $\varepsilon$ is set according to the thermal limits of the semiconductor devices to ensure the semiconductors operating within safe junction temperature. As suggested in [5], when frequencies are lower than $5 \mathrm{~Hz}$ (corresponding to rotor speed of 0.1 p.u. in system with a normal frequency of $50 \mathrm{~Hz}$ ), the junction temperature follows power dissipation, which results in high temperature fluctuation. It is also recommended in [10] that derating of the converter is necessary when rotor frequencies are lower than 0.1 p.u. Otherwise, the relationship between the junction temperature and rotor current frequencies should be determined through an experiment as outlined in $[7,18]$ to set the value for $\varepsilon$. In this paper, since the DFIG is operating at unity power factor, the rotor current is less than its rated value (as used in the case where $\varepsilon$ is set at 0.1 p.u.) when DFIG operates around synchronous speed. Therefore, the deadband can be smaller and $\varepsilon$ is adjusted to be at 0.02 p.u., which corresponds to a slip frequency of $1 \mathrm{~Hz}$.

1) DFIG Mode: when the rotor speed is outside the deadband, the WECS operates as a typical DFIG. The equivalent circuit of the generator is shown in Fig. 4-(a).

2) IG Mode: when the rotor speed is less than $\left(\omega_{\mathrm{s}}+\varepsilon\right)$ or larger than $\left(\omega_{\mathrm{s}}-\varepsilon\right)$, the crowbar circuit is activated by connecting an external resistance to the rotor windings while RSC is disabled. As a consequence, the DFIG becomes an induction generator. The equivalent circuit of the generator at IG mode is shown in Fig. 4-(b).

Another strategy to rectify this excessive heating issue around synchronous speed is the suboptimal power point tracking (SOPPT) approach proposed in [19]. In the SOPPT approach, it simply shifts the rotor speed to a certain value outside the deadband to avoid the synchronous operation. However, the constant speed operation can cause significant torque stress on the drive-train. Furthermore, an anemometer is required to monitor the wind speed to determine the suitable time to shift back to maximum power point tracking (MPPT) operation mode. The wind speed measurement accuracy directly affects the effectiveness of the strategy based on the SOPPT. These two drawbacks can be avoided with the multimode operation strategy.

It is also important to be noted that the LVRT has higher priority over the deadband control of synchronous operation and the system will sacrifice its component lifetime to maintain the stability of the system under contingency. With the proposed control strategy, the multi-mode operation mechanism is only active under normal grid voltage condition and the mode transition is not activated under grid faults. The deadband control will not be enabled until grid fault is cleared and the LVRT operation is reset. Hence, the conflict between deadband control and LVRT control can be avoided.

\section{IV.SUPPLEMENTARY CONTROL FOR MULTI-MODE OPERATION}

From the equivalent circuit of the DFIG in Fig. 4-(a), the electromagnetic torque of the generator under DFIG mode can be determined by;

$$
T_{D F I G}=\frac{3 p R_{r}}{\omega_{r}}\left(\frac{1-s}{s}\right)\left|I_{r}\right|^{2}-\frac{3 p}{\omega_{r}}\left(\frac{1-s}{s}\right) \operatorname{Re}\left(V_{r} \cdot I_{r}^{*}\right)
$$

where $p$ is the number of pole pairs, $R_{r}$ is the rotor resistance referred to the stator side, and $\operatorname{Re}\left(V_{r} \cdot I_{r}^{*}\right)$ indicates the real part of the multiplication of the rotor voltage phasor and current phasor conjugate. As explained in [16], (1) can be further extended as (2) and the terms of (2) are given in [16]. 


$$
\begin{aligned}
T_{D F I G}= & 3 \frac{L_{m}}{\sigma L_{r} L_{s}} p F^{2}\left\{C_{s} C_{r}\left|V_{s}\right|\left|V_{r}\right| \sin \varphi+A_{r} C_{r}\left|V_{s}\right|^{2} \sin B_{r}\right. \\
& \left.-A_{s} C_{r}\left|V_{s}\right|^{2} \sin B_{s}-A_{s} A_{r}\left|V_{s}\right|\left|V_{r}\right| \sin \left(\varphi+B_{s}-B_{r}\right)\right\}
\end{aligned}
$$

Similarly, the electromagnetic torque of the generator under the IG mode is given by;

$$
T_{I G}=\frac{3 p\left(R_{r}+R_{c b}\right)}{\omega_{r}}\left(\frac{1-s}{s}\right)\left|I_{r}\right|^{2}
$$

where $R_{c b}$ is the crowbar resistance referred to the stator side. Using Thévenin's Theorem, (3) can be extended as (4).

$$
T_{I G}=\frac{3 p\left(R_{r}+R_{c b}\right)}{\omega_{r}}\left(\frac{1-s}{s}\right) \frac{V_{T H}^{2}}{\left[R_{T H}+\left(R_{r}+R_{c b}\right) / s\right]^{2}+\left(\omega_{s} L_{T H}+\omega_{s} L_{r}\right)^{2}}
$$

The Thévenin voltage and impedance are given by (5) and (6) respectively.

$$
\begin{array}{r}
V_{T H}=\frac{j \omega_{s} L_{m}}{\left(R_{s}+j \omega_{s} L_{s}\right)+j \omega_{s} L_{m}} V_{s} \angle 0 \\
R_{T H}+j \omega_{s} L_{T H}=\frac{\left(R_{s}+j \omega_{s} L_{s}\right) \cdot j \omega_{s} L_{m}}{\left(R_{s}+j \omega_{s} L_{s}\right)+j \omega_{s} L_{m}}
\end{array}
$$

where $L_{\mathrm{m}}$ is the magnetizing inductance, $L_{\mathrm{s}}$ is the stator leakage inductance, and $R_{\mathrm{s}}$ is the stator resistance.

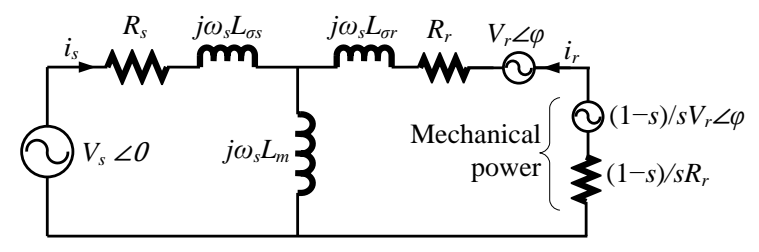

(a)

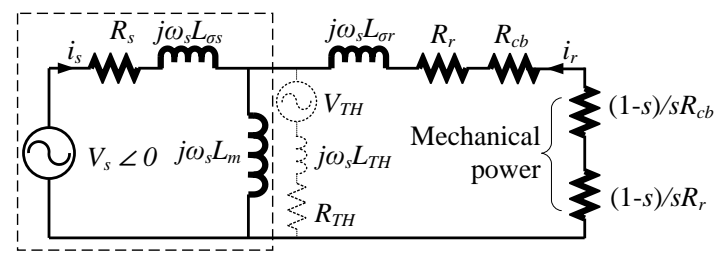

(b)

Fig. 4 Equivalent circuits of the generator. (a) DFIG mode. (b) IG mode.

In DFIG mode, the machine is controllable through the RSC. As (2) shows, the electromagnetic torque is controlled by adjusting the phase angle $(\varphi)$ and magnitude of the rotor voltage $\left(V_{\mathrm{r}}\right)$. Contrarily, the controllability is lost when the crowbar short-circuits the rotor. As indicated by (4), with a fixed stator terminal voltage and crowbar resistance, the electromagnetic torque cannot be controlled externally in IG mode. In order to achieve a smooth transition between these two operating modes, the electromagnetic torque in both operating modes is expected to be more or less the same when the transition is taking place. Hence, the torque transient on the drive-train of the DFIG can be alleviated. Therefore, supplementary control strategies should be implemented in the torque controller as shown in Fig. 1, in order to provide a torque reference to the RSC controller and modify the electromagnetic torque to match with the mechanical torque.

\section{A. Transition from DFIG Mode to IG Mode}

Fig. 5 shows the torque-speed curves of a wind turbine at variable wind speeds. Typically, the wind turbine is controlled to operate at the speed where wind energy extraction is maximized. The tracking curve is indicated by thick dashed line in Fig. 5, and there is one section within the range $\left[\omega_{\mathrm{s}}-\varepsilon, \omega_{\mathrm{s}}+\varepsilon\right]$ which should be avoided as explained in Section II. Thus, this section is set as the deadband for the DFIG mode operation, and the operating mode of the WECS should be altered to IG mode when rotor speed reaches the deadband. Under steadystate condition in IG mode, the equilibrium point (which is the intersection of the torque speed curve of the WRIM and the torque-speed characteristic curve of the wind turbine at a particular wind speed) under IG mode operation is dependent on the crowbar resistance. For example, the green dash-dot line in Fig. 5 is the torque-speed curve with the rotor windings shortcircuited (i.e. $R=R_{r}$ ). By connecting an external crowbar resistance into the rotor circuit, the equivalent rotor resistance is increased (i.e. $R=R_{r}+R_{c b}$ ). The modified torque-speed curve of the WRIM has the shape indicated by the blue dash-dot line in Fig. 5. Although the direct short-circuit of the rotor has better operating efficiency, additional hardware configuration is required for the DFIG to enable this operation, and the narrower operating speed range due to lower total rotor resistance significantly stresses the drive-train. Hence, existing crowbar is applied to alter the DFIG operation modes in this paper. With the characteristic curves of the wind turbine and WRIM, the wind speeds which drive the DFIG operation within the deadband $\left[\omega_{\mathrm{s}}-\varepsilon, \omega_{\mathrm{s}}+\varepsilon\right]$ can be determined. Then the intersections of the torque speed curve (i.e. the blue curve) of the WRIM and the torque-speed characteristic curves of the wind turbine can be obtained under the corresponding wind speeds. Thus, the speed range $\left[\omega_{1}, \omega_{\mathrm{h}}\right]$ for IG mode operation can be determined.

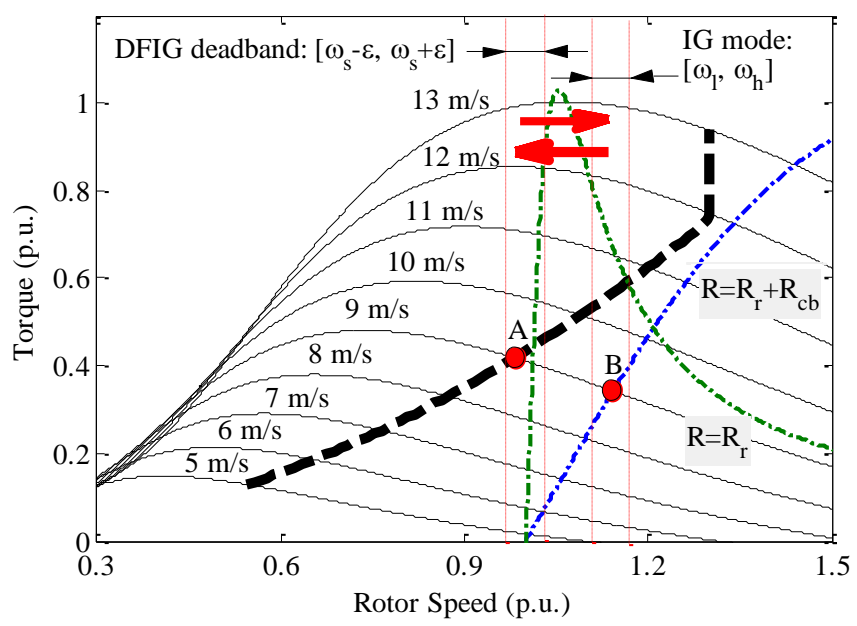

Fig. 5 Torque speed curve of a wind turbine at variable wind speed.

To achieve a smooth transition from the DFIG mode to the IG mode, the electromagnetic torque should be adjusted to be equal in the two different modes at the time of transition. Therefore, when the DFIG rotor speed is within the deadband, 
the operating point is shifted intentionally away from the optimal point (e.g. point A) to the operating point in IG mode (e.g. point B) before activating the transition. The control logic is illustrated in the flowchart shown in Fig. 6. The DFIG is controlled by the torque regulator to change the rotor speed to the IG mode operating speed range. To avoid frequent mode transitions, hysteresis control is used to detect the rotor speed and a moving average method is used to measure the rotor speed.

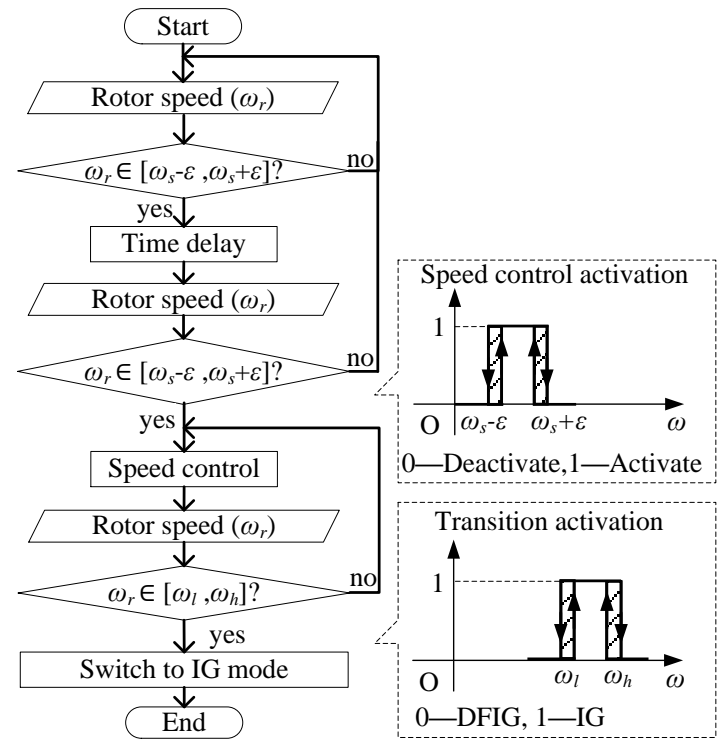

Fig. 6 Flowchart of transition from DFIG mode to IG mode.

\section{B. Transition from IG Mode to DFIG Mode}

In IG mode, the generator consumes reactive power from other reactive power sources for excitation. Hence, additional reactive power support should be provided to improve the power factor of the DFIG during the IG mode operation. Capacitors are commonly used for standard IG based WECS, but similar capacitors may not be installed for DFIGs. As suggested in [20], the GSC in combination with the DC-link can be used as a reactive power source. In this paper, the GSC is used to supply reactive power for the excitation of the generator itself, thus acting as a STATCOM in IG mode to correct the power factor seen by the grid. The reactive power capability of the GSC can be fully utilized with no active power transfer and it is not compromised by grid faults, since the transition is carried out under normal operation. Power factor control is implemented in the GSC controller. With the power factor $(P F)$ set by the wind farm system level control, and the actual active power $\left(P_{0}\right)$ generated from the generator, the reactive power reference $\left(Q_{\text {ref }}\right)$ for the GSC controller can be obtained using (7).

$$
Q_{\text {ref }}=\sqrt{\left(\frac{1}{P F^{2}}-1\right)} P_{0}
$$

For example, $Q_{\text {ref }}$ is set to be zero if the generator is expected to be operated at unity power factor. The reactive power control logic is shown in Fig. 7. The input to the VAr regulator is the error between the reactive power reference and actual
DFIG system reactive power output $\left(Q_{0}\right)$. The GSC $q$-axis current reference (which controls the reactive power in grid voltage oriented reference frame with $d$-axis aligned with the voltage) is supplied. The transition signal ensures the supplementary reactive power control is only activated under IG mode.

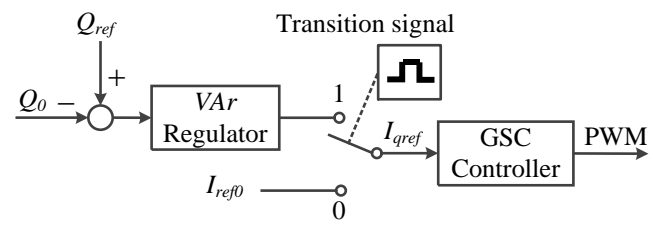

Fig. 7 Reactive power control using GSC.

Moreover, grid codes generally have power factor limitations (e.g. 0.95 lagging to 0.95 leading under normal grid condition) for grid-connected wind turbine generators to support voltage regulation; and extra reactive power support can also be required under fault conditions (e.g. voltage dips) [21]. If the grid demands the generator to absorb reactive power from the grid within the permissible power factor range (i.e. lagging power factor), the reactive power supplied from the GSC can be reduced and the burden on the GSC is reduced while the grid code can be satisfied. However, if the generator is expected to supply reactive power to the grid (i.e. leading power factor) in IG mode, the GSC should supply reactive power to the generator as well as the grid and it will be highly stressed or may not have enough reactive power capability to support voltage regulation. Hence, higher capacity might be required for the GSC. Nevertheless, it is important to note that the grid codes are normally by the voltage support requirements at the point of common coupling (PCC) where the wind farm is interfaced to the grid. The coordinated control among wind turbine generators in the wind farm could be able to satisfy the reactive power requirement, since it is unlikely that all wind turbine generators in the wind farm will operate in IG mode simultaneously. Furthermore, extra reactive power resources like STATCOM, SVC, etc. are generally equipped for wind farms at the PCC to support voltage regulation [22].

In IG mode, when the rotor speed exceeds the IG operation range $\left[\omega_{l}, \omega_{h}\right]$, the generator shifts back to the DFIG mode. Since the RSC loses the control of the generator in IG mode, the torque of the IG cannot be actively controlled. Nevertheless, due to the fast response of electromagnetic torque control, the generator is able to track to the electromagnetic torque reference rapidly after switching back to the DFIG mode. If improper torque reference is provided, large torque transient is expected due to the mismatch between the mechanical torque and electromagnetic torque. Therefore, the torque reference provided by the torque controller should be able to closely follow the mechanical torque during the IG mode operation and an anti-windup control loop is added into the torque controller as shown in Fig. 8. Without the anti-windup control, an error presented between the actual rotor speed and rotor speed reference provided by the MPPT control will drive the torque reference to its limit, causing a sudden shock on the drive-train and large oscillations in the rotor speed during transition. 
When the anti-windup control is applied, the electromagnetic torque reference can closely follow the mechanical torque by feeding back the error between torque reference and mechanical torque to the speed regulator. Hence, the high torque stress on the drive-train can be alleviated. A similar supplementary controller is used in [19] to provide enhanced primary frequency response from the DFIG. The implementation of the supplementary control in this paper further extends the benefits of the supplementary control of the frequency regulation.

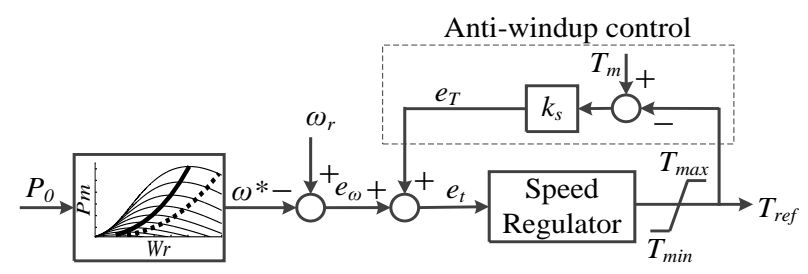

Fig. 8 Torque controller with anti-windup control.

\section{THERMAL ANALYSIS OF DFIG COMPONENTS}

\section{A. Thermal Analysis of Semiconductor Devices}

The procedure of thermal analysis for semiconductor devices in this paper is presented in Fig. 9. The electrical loading signals from the DFIG electrical model as shown in Fig. 1, such as DC-link voltage $\left(V_{\mathrm{DC}}\right)$, RSC switching frequency $\left(f_{\mathrm{sw}}\right)$ and RSC currents, are fed into an energy loss calculation function, from which power loss $\left(P_{\text {loss }}\right)$ of the semiconductors can be calculated, and then the semiconductor junction temperature $\left(T_{\mathrm{j}}\right)$ can be estimated with the thermal network of the semiconductor devices. The temperature is feedback to the loss calculation function to reflect the temperature dependency of the losses.

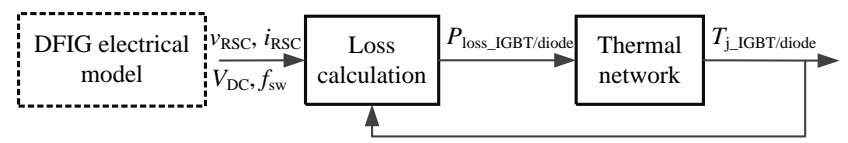

Fig. 9 Thermal analysis model.

The energy loss of semiconductor devices are mainly composed of two parts: conduction loss and switching losses. The conduction loss of the IGBT and freewheeling diode can be determined by (8) and (9) respectively [7].

$$
\begin{aligned}
& E_{\text {con_IGBT }}\left(i_{T}, T_{j}\right)=\int_{0}^{T} i_{T}(t) \cdot\left[v_{c e 0}\left(T_{j}\right)+r_{c e}\left(T_{j}\right) \cdot i_{T}(t)\right] d t \\
& E_{\text {con_diode }}\left(i_{D}, T_{j}\right)=\int_{0}^{T} i_{D}(t) \cdot\left[v_{f 0}\left(T_{j}\right)+r_{f}\left(T_{j}\right) \cdot i_{D}(t)\right] d t
\end{aligned}
$$

where $v_{\mathrm{ce} 0}$ and $v_{\mathrm{f} 0}$ are the threshold voltage of the IGBT and diode respectively, $r_{\mathrm{ce}}$ and $r_{\mathrm{f}}$ are the bulk resistance of IGBT and diode respectively, and $i_{\mathrm{T}}$ and $i_{\mathrm{D}}$ are the current flowing through IGBT and diode respectively.

In regard to the switching losses of an IGBT and diode, it depends on the load current, DC link voltage and junction temperature as given by (10) and (11) [5, 14].

$$
\begin{aligned}
E_{s w_{-} I G B T}\left(i, V_{D C}, T_{j}\right)= & \left(E_{\text {on }}+E_{\text {off }}\right) \cdot \frac{i}{I_{r e f}} \cdot\left(\frac{V_{D C}}{V_{r e f}}\right)^{K_{v}} \\
\cdot & {\left[1+C_{s w} \cdot\left(T_{j}-T_{r e f}\right)\right] } \\
E_{s w_{-} \text {diode }}\left(i, V_{D C}, T_{j}\right)= & E_{r r} \cdot\left(\frac{i}{I_{r e f}}\right)^{K_{i}} \cdot\left(\frac{V_{D C}}{V_{r e f}}\right)^{K_{v}} \\
& \cdot\left[1+C_{r r} \cdot\left(T_{j}-T_{r e f}\right)\right]
\end{aligned}
$$

where $I_{\text {ref }}, V_{\text {ref, }}$ and $T_{\text {ref }}$ are the current, voltage, and temperature respectively, when the switching loss is measured as given in the datasheet of the semiconductor devices. $K_{\mathrm{v}}$ and $K_{i}$ are the exponents for voltage and current dependency of the switching loss respectively. $\mathrm{C}_{\mathrm{sw}}$ and $\mathrm{C}_{\mathrm{rr}}$ are the temperature coefficients of switching loss for IGBT and diode respectively. In this study, the SEMIKRON IGBT module SKiiP 2013 GB172-4DW V3 [17] is used for thermal analysis. The values for these parameters can be found in $[5,17]$.

The Foster network [5] is used as the model for the thermal network used in this paper to estimate the junction temperature which is determined by (12);

$$
T_{j T / D}=\left(P_{\text {conT/D }}+P_{s w T / D}\right) \cdot \operatorname{Rth}_{(j-h) T / D}+T_{h}
$$

where $P_{\text {con }}$ and $P_{\text {sw }}$ are the conduction power loss and switching power loss respectively for an IGBT or diode, $R t h_{\mathrm{j}-\mathrm{h}}$ is the thermal resistance between the junction and heat sink, and $T_{\mathrm{h}}$ is the temperature of heat sink which is given by (13).

$$
T_{h}=P_{t o t} \cdot \operatorname{Rth}_{h-a}+T_{a}
$$

where $P_{\text {tot }}$ is the total power loss of the semiconductors, $R t h_{\mathrm{h}-\mathrm{a}}$ is the thermal resistance between heat sink and ambient which is taken as $0.093 \mathrm{~K} / \mathrm{W}$ in the case studies below. $T_{\mathrm{a}}$ is the ambient temperature chosen as $50{ }^{\circ} \mathrm{C}$ [9] in this paper.

\section{B. Thermal Energy Capacity of Crowbar}

According to current grid codes the crowbar operation during LVRT is limited to $3 \mathrm{~s}$ [21]. In this paper, the multimode operation intends to operate the crowbar for a longer time, so it is imperative to investigate the thermal performance of the crowbar during multimode operation. The rotor overcurrent under grid faults can be up to three times the nominal current [2]. Contrarily, when the DFIG operates in IG mode around the synchronous speed as proposed in this paper, the rotor current is much smaller than the nominal current. For example, the 1.5 MW DFIG considered in this paper has a rated rotor current of $880 \mathrm{~A}$, and the rotor current under IG mode is approximately $350 \mathrm{~A}$. Hence, the power consumed by the crowbar under IG mode is substantially less than under fault conditions. The thermal time constant of the crowbar is generally high enough to handle the rotor fault currents. A commercial crowbar resistor (model: FLWR-2040 KJ/0.17R) [23], which has an energy rating of $2040 \mathrm{~kJ}$, resistance of $0.17 \Omega$, and operating time of $3 \mathrm{~s}$, has been used as the LVRT crowbar for the DFIG in this study. Using (14), the rated crowbar cur- 
rent (by assuming $3 \mathrm{~s}$ operation of the crowbar during LVRT) is calculated to be $2000 \mathrm{~A}$, and thus it can be shown that the crowbar is capable of operating around $100 \mathrm{~s}(t=$ $\left.2040 \times 10^{3} /\left(350^{2} \times 0.17\right)\right)$ under IG mode without overheating the crowbar. Also it must be noted that the improvement in self-cooling effect due to low crowbar current is not considered in this calculation, hence the crowbar can be actually operated much longer than $100 \mathrm{~s}$ under IG mode.

$$
I=\sqrt{\frac{E}{t R}}
$$

Therefore, no hardware modifications are required for existing DFIG, such as cooling systems etc. to implement the deadband control strategy proposed in this paper. It is also important to acknowledge that IG mode is just a temporary operating mode considering the continuous variation in wind speed. Fast cyclic IG mode operation can be avoided as exemplified in Section VI-D.

\section{VI.PERFORMANCE OF THE MULTI-MODE OPERATION}

The proposed control strategy can be used in both gridconnected WECS and remote area power supply (RAPS) systems which are 'islanded' power system. In this paper, a hypothetical RAPS system is established in the SimPowerSystems platform to investigate the performance of the multi-mode controller, and the details of the system are given in Fig. 10. RAPS systems are constituted of small number of generators and the total capacity is usually small. Power management is more challenging and stability is more critical to manage in comparison to a grid-connected system. By validating new control strategies through such system can show the effectiveness of the control strategy even under the worst case scenario. The loads in the system are mainly powered by a diesel generator and a DFIG. The diesel generator establishes the system by providing frequency and voltage reference. The DFIG is expected to support the system while operating at unity power factor. A similar system has also been explored in [19] to verify the frequency response strategy, but the control strategies and loads are adjusted to test the proposed control strategy.

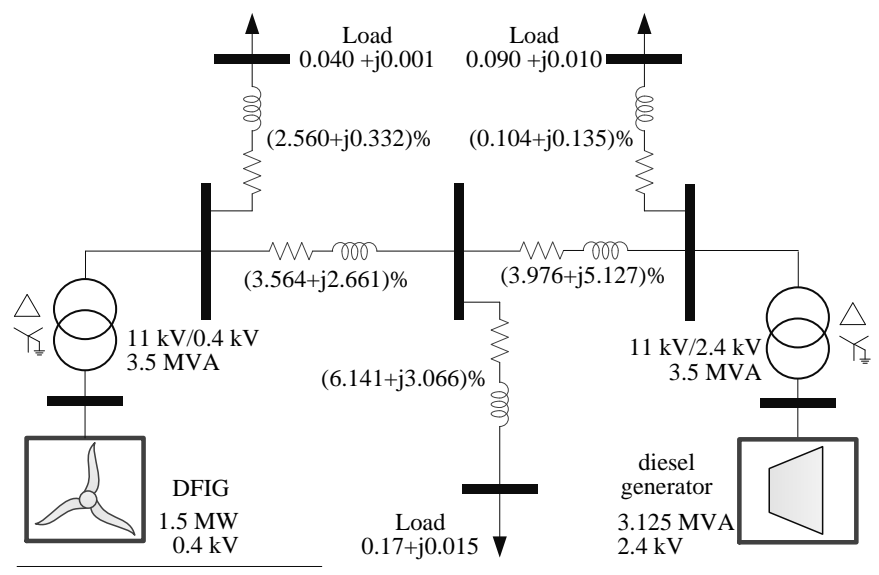

$S_{\text {base }}=10 \mathrm{MVA}, V_{\text {base }}=11 \mathrm{kV}$

Fig. 10 Architecture of the test system.

\section{A. Transition from DFIG Mode to IG Mode}

When the rotor speed reaches the deadband under DFIG mode as detailed in Fig. 6, the operating mode of the DFIG is altered. As shown in Fig. 11, a step increase in wind speed causes the rotor speed to increase at $t=75 \mathrm{~s}$.

If the speed regulation (see Section IV-(A)) is not implemented, the DFIG switches to IG mode immediately, which causes large transient in the DFIG itself as well as the RAPS system. The sudden removal of the rotor voltage causes the rotor current to decay and, the collapse of the rotor magnetic field results in the loss of electromagnetic torque (see blue dotted curve in Fig. 11-(c)). Hence, the power output from the DFIG drops abruptly to zero as presented by the blue dotted curve in Fig. 11-(a). Furthermore, the violent variation in electromagnetic torque will also exert additional stress on the drive-train. As seen in Fig. 11-(d), the mechanical torque decreases sharply and oscillates before reaching new steadystate, attributing to a sudden increase and oscillation in rotor speed (see blue dotted curve in Fig. 11-(b)). Contrarily, with the proposed control strategy, the transition from the DFIG mode to the IG mode is smoothed significantly. At around $t=$ $75 \mathrm{~s}$, the DFIG starts to adjust the speed (thus torque) to match with the speed under the IG mode. The DFIG switches from the DFIG mode to the IG mode around $t=92 \mathrm{~s}$. At the moment of transition, only minor disturbances are observed in power output, system frequency, and torques.
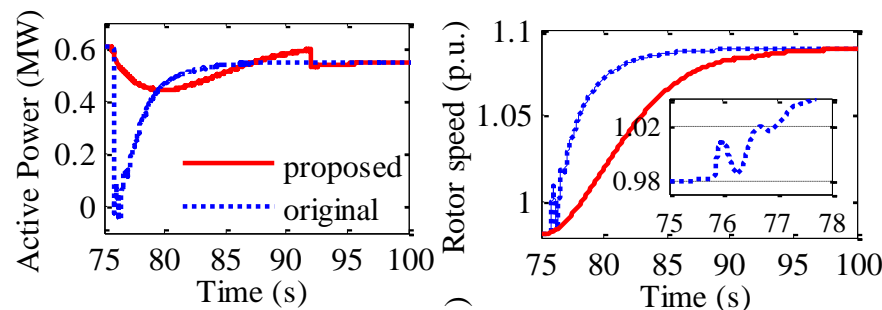

(a)

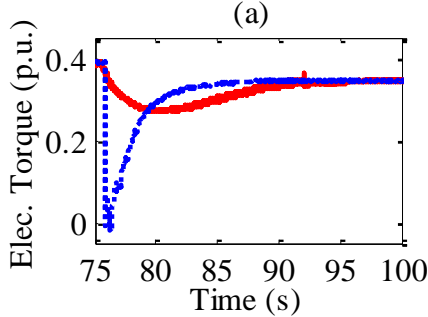

(c)

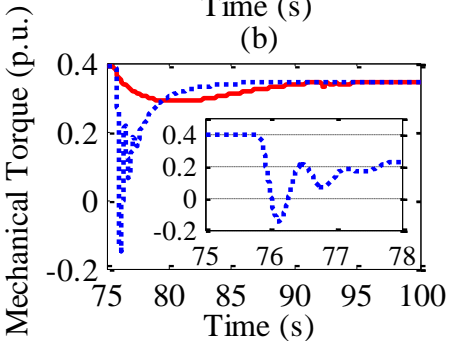

(d)

Fig. 11 The DFIG switches from DFIG mode to IG mode. (a) DFIG active power output. (b) DFIG rotor speed. (c) DFIG electromagnetic torque. (d) DFIG mechanical torque.

\section{B. Transition from IG Mode to DFIG Mode}

As explained in Section IV-(B), if the proposed anti-windup control strategy is not implemented, the error between the actual rotor speed and reference value, will increase the torque reference value to its limits. The electromagnetic torque follows the reference rapidly (see blue dotted curve in Fig. 12(c)) and a large difference is observed between the mechanical and electromagnetic torques, which brings enormous torque stress on the drive-train and an almost step change in rotor speed is resulted as shown by the blue dotted curve in Fig. 12- 
(b). A large oscillation in mechanical torque is observed in the zoomed section in Fig. 12-(d).

Meanwhile, an active power surge can also be observed at the DFIG as indicated by the blue dotted curve in Fig. 12-(a). With the proposed anti-windup control, the electromagnetic torque reference tracks the mechanical torque during the IG mode operation. At the moment of mode transition, the torque difference between the mechanical torque and electromagnetic torque is narrowed. Consequently, large transients are avoided and a smooth transition from the IG mode to the DFIG mode is achieved.

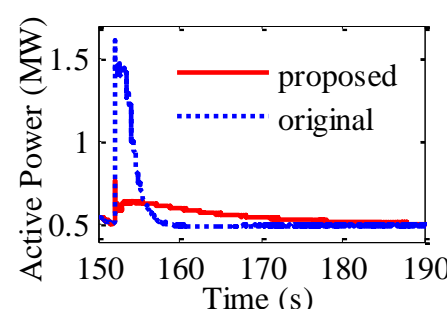

(a)

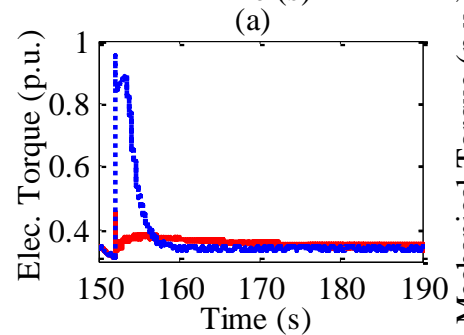

(c)
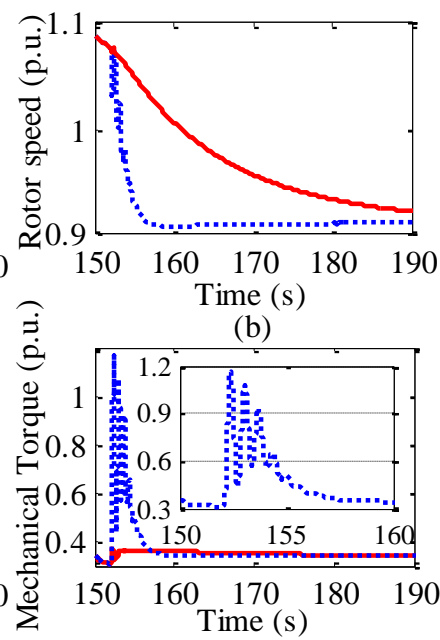

(d)

Fig. 12 WECS switches from IG mode to DFIG mode; (a) DFIG active power output, (b) DFIG rotor speed, (c) DFIG electromagnetic torque, (d) DFIG mechanical torque.

\section{Operation under Variable Wind Speed}

For the case studies presented in Sections VI-(A) and (B), a step change in wind speed is used to investigate the dynamic performance of the WECS during the transition period. In order to validate the effectiveness of the proposed strategy under a more practical scenario, a $250 \mathrm{~s}$ variable wind speed profile is applied to the DFIG. The performance of the DFIG under variable wind conditions are shown in Fig. 13.

The wind speed profile is shown in Fig. 13-(a). Initially, the DFIG is operating in DFIG mode and the rotor speed $\left(\omega_{r}\right)$ is below synchronous speed, as shown in Fig. 13-(f) and thus, the GSC is absorbing power $\left(P_{g s c}\right)$ from the grid (indicated by positive values as shown in Fig. 13-(d)). Since the GSC is operating under unity power factor, the reactive power flow $\left(Q_{g s c}\right)$ at the GSC is zero (see Fig. 13-(e)). Fig. 13-(b) and (c) show the active power $\left(P_{0}\right)$ and reactive power $\left(Q_{0}\right)$ interaction respectively between the DFIG and the grid. The DFIG does not participate in reactive power support for the grid, and operates closer to the unity power factor to satisfy the power factor requirement set by the utility.

Around $t=30$ to $40 \mathrm{~s}$, the rotor speed is detected to be within the designated deadband (i.e. $\left[\omega_{s}-\varepsilon, \omega_{s}+\varepsilon\right]$ ) for DFIG operation. Hence, the speed regulation is activated; the speed regulation period is shadowed in Fig. 13. The rotor speed increases and power output from the DFIG decreases, since the operat- ing point of the DFIG is shifting away from the point set by MPPT control. Nevertheless, the financial benefit will not be compromised significantly, because the WECS temporarily operates in IG mode considering the continuous variation in wind speed. The GSC starts to provide active power when the rotor speed exceeds the synchronous speed. At the moment when the rotor speed reaches the range $\left[\omega_{l}, \omega_{h}\right]$, the crowbar is activated to short-circuit the rotor windings and the RSC is blocked. The mode transition takes place around $t=60 \mathrm{~s}$ in this case.

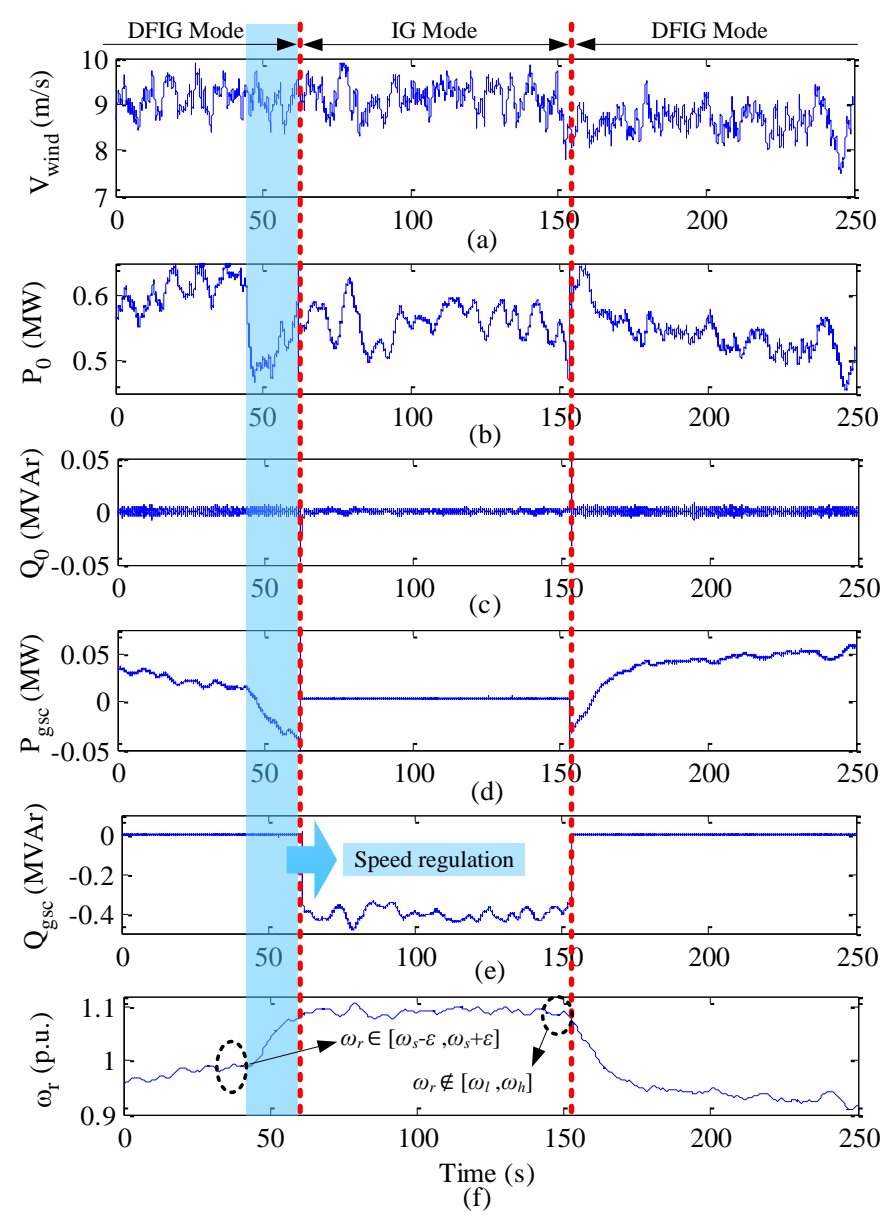

Fig. 13 The DFIG operation under variable speed; (a) Wind speed profile, (b) DFIG active power output, (c) DFIG reactive power output, (d) GSC active power output, (e) GSC reactive power output. (f) DFIG rotor speed.

From Fig. 13, it can be seen that abrupt changes only occur at the power output from the GSC, which indicates the smooth transition from the DFIG mode to the IG mode. The active power output at the GSC suddenly decreases to zero (see Fig. 13-(d)) due to the zero active power flow from rotor windings to the DC-link when the RSC is disabled. As described in Section IV-B, the zero active power output from the GSC leaves the capacity of the GSC for reactive power support. Therefore, the GSC operates as a STATCOM to fulfil the reactive power requirement of the DFIG under the IG mode, and hence the reactive power output from the GSC is no longer zero, as shown in Fig. 13-(e). Consequently, the grid does not supply any reactive power to the DFIG (under IG mode) and unity power factor operation is maintained as shown in Fig. 13-(c). 
The DFIG operates as an induction generator until the wind speed ramps down at around $t=150 \mathrm{~s}$. It is worth to be noted that an additional advantage of the IG mode operation is that it can enhance the frequency support by providing a natural inertial response by using its stored kinetic energy without any control intervention [24].

On the declining in wind speed from $t=150 \mathrm{~s}$, the rotor speed decreases and the demand for switching WECS back to the DFIG mode is activated when the rotor speed is detected to be out of the range $\left[\omega_{l}, \omega_{h}\right]$. The crowbar mechanism is deactivated and the RSC is activated. The DFIG slowly shifts to steady-state operation under DFIG mode. The GSC stops providing reactive power and starts to deliver active power again as seen in Figs. 13-(e) and (d) respectively.

The three phase-currents in rotor windings are shown in Fig. 14. The upper left zoomed figure in Fig. 14 shows that the frequency of rotor currents is approximately $0.5 \mathrm{~Hz}$ before the DFIG switches from DFIG mode to IG mode. As explained in Section III, the low frequency of the rotor currents can cause thermal problems for the semiconductor devices of the RSC. The instantaneous power loss and junction temperature are shown in Fig. 15-(a) and (b) respectively for the upper IGBT and lower diode in one leg of the RSC. Since the IGBT and the diode turn on and turn off simultaneously, the instantaneous power loss of each component is coincidental, as shown in Fig. 15-(a), and the corresponding temperature of each component is also presented in the zoomed graphic in Fig. 15-(b). Although the power loss of the IGBT is higher than the diode between 35 to $45 \mathrm{~s}$, the temperature of the IGBT is roughly the same as the diode, which is due to the lower junction-toheatsink thermal resistance of IGBT compared to diode. An additional lower peak in the temperature waveform can be observed between two adjacent higher peaks, which is due to the thermal coupling effect between the IGBT and its antiparallel diode since the two chips are placed on the same base plate and close to each other. The coupling effect becomes stronger when the current frequency is low and hence further increases the junction temperature fluctuation. The heating of the antiparallel diode in the second half of the fundamental period adds to the heating of the IGBT on the same base plate.

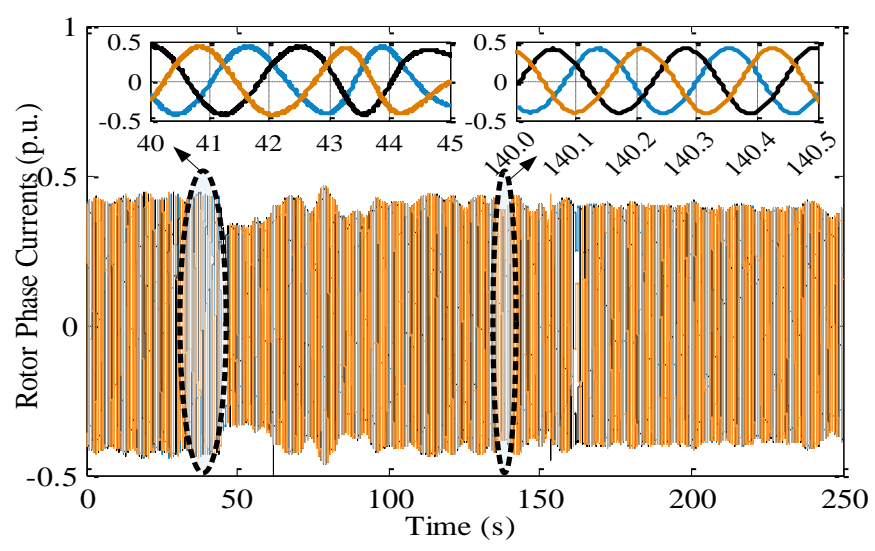

Fig. 14 Three-phase currents in rotor windings.
The upper right zoomed figure in Fig. 14 presents the rotor currents when the DFIG is operating in IG mode, and higher frequency of rotor currents can be observed. Hence, rotor currents of very low frequency are avoided. Due to the subsynchronous and super-synchronous operation in DFIG and IG mode respectively, the phase sequences of the rotor currents change with the mode transition. Since the RSC is blocked in IG mode, it can be seen from Fig. 15-(b) that semiconductor devices are cooled down in IG mode.
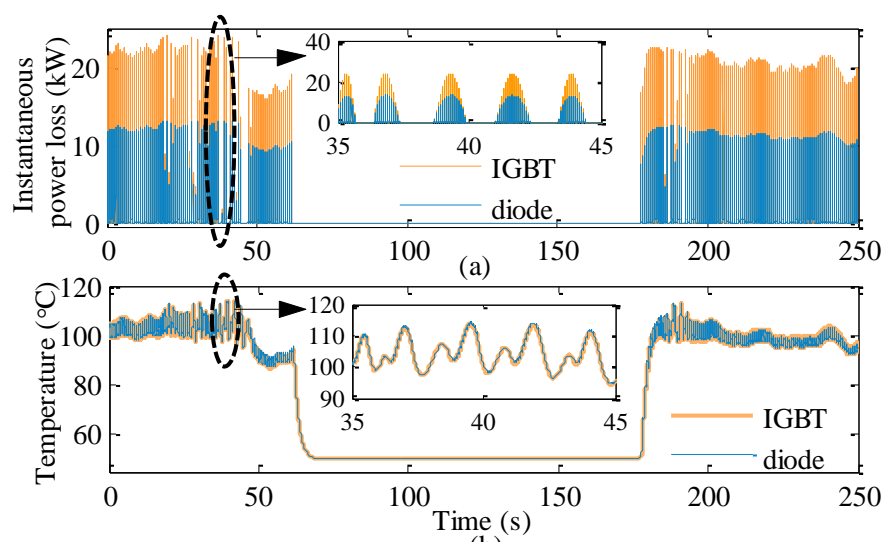

(b)

Fig. 15 Thermal performance of the IGBT and diode. (a) Instantaneous power losses. (b) Junction temperature.

\section{Riding through Synchronous Speed}

Long-term operation around synchronous speed can be avoided with the proposed control strategy for the DFIG, and the operating mode of the DFIG is not expected to be changed if the rotor speed passes the synchronous speed rapidly due to large wind speed variations. Hence, the operating mode alternation will not be activated if the DFIG can ride-through the synchronous speed within a predefined time period. For example, the average wind speed increases from $8.5 \mathrm{~m} / \mathrm{s}$ to 10 $\mathrm{m} / \mathrm{s}$ with a ramp rate of $0.05 \mathrm{~m} / \mathrm{s}^{2}$ (see Fig. 16), the operating mode is not changed. If the ramp rate of wind speed is lower than $0.05 \mathrm{~m} / \mathrm{s}^{2}$, the mode transition will be activated, since the rotor speed stays within the deadband for a longer period of time, and the junction temperature increase may damage the semiconductor devices.
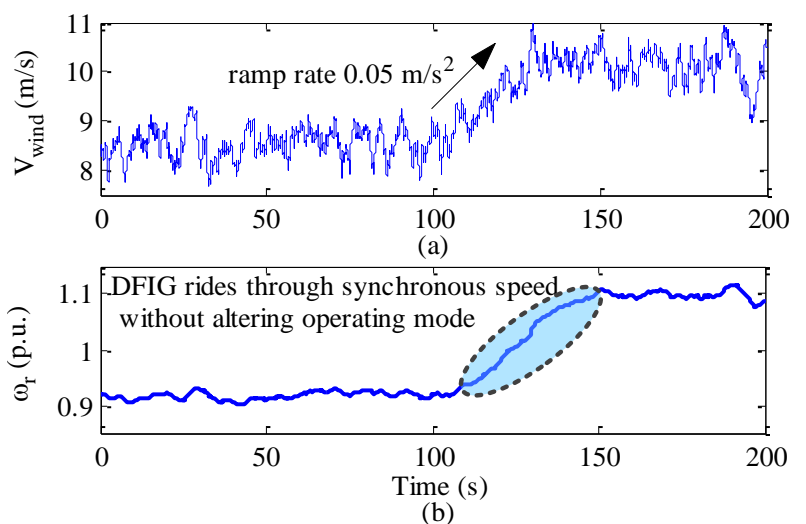

Fig. 16 The DFIG operation during wind speed ramp-up scenario. (a) Wind speed profile. (b) DFIG rotor speed. 
The time that rotor speed takes to ride though the deadband can be approximated based on the ramp rate of wind speed and the mechanical dynamics of the wind turbine. Considering the permissible time that a semiconductor device can safely operate at maximum junction temperature, the critical ramp rate of wind speed should be set to ensure the ride-though time does not exceed the permissible operating time. Additionally, the wind speed (i.e. $11 \mathrm{~m} / \mathrm{s}$ in this paper) at the rated power output of the wind turbine is well above the wind speeds (i.e. around $9 \mathrm{~m} / \mathrm{s}$ in this paper) under which the DFIG rotor speed is within the deadband. Hence, according to the probability density function of the wind speed for a typical wind farm location, the likelihood of DFIG operating in the IG mode is low. Therefore, the temperature swing due to the RSC on and off is not frequent and the financial loss due to the non-optimal operation under IG mode is limited while reliability of the DFIG can be improved with the extended service life of the semiconductor devices.

\section{PROOF OF CONCEPTS USING EXPERIMENTAL TEST BED}

The effectiveness of the proposed control strategy is verified by extensive simulation studies presented in Section VI. Due to the fact that the IGBT junction temperature and its power loss related to thermal analysis are not available as a direct measurement in practical experiment, simulation is a good alternative way to validate the proposed control strategy. In this section, some experimental results are provided to prove the concept of multimode operation using the test system as shown in Fig. 17.

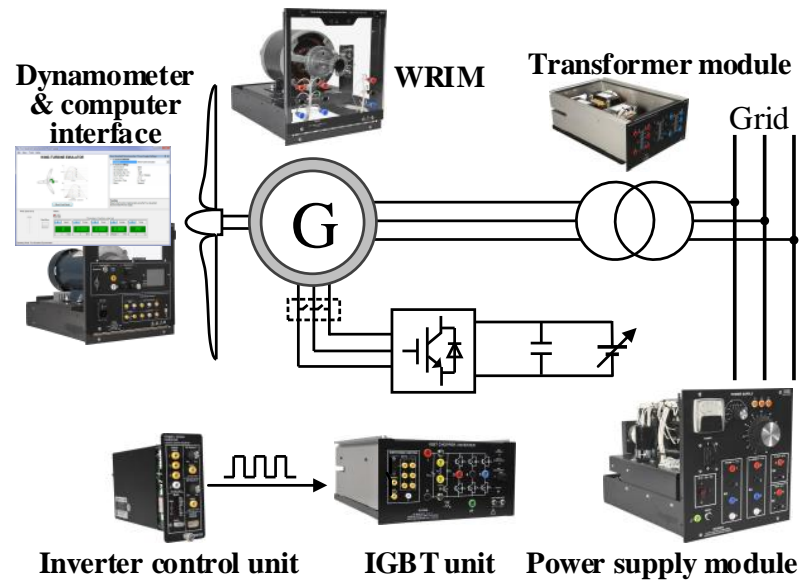

Fig. 17 Architecture of the test system.

The system is developed based on the LabVolt ${ }^{\circledR}$ electric power technology training system with the guidelines and parameters given in [25]. A wound rotor induction machine module is used as the generator, whereas a dynamometer module emulates the wind turbine with its characteristic controlled by the computer interface. Since the purpose of the test is to observe the dynamics in rotor currents, stator currents as well as rotor speed and torque during mode transitions, the back-to-back converter scheme and its control are simplified. An IGBT based inverter unit is used for the RSC, while the DC-link is connected to a variable DC voltage source. In case of super-synchronous operation, the rotor power is absorbed by a dump resistor across the DC-link. The RSC is manually controlled by the inverter control unit to vary its output fundamental frequency, and the variable voltage DC-link controls the rotor voltage magnitude. Besides, no external resistance is added into the crowbar because no fault study is carried out in this paper. Consequently, the system operates in the same principle as a normal DFIG apart from the lack of physical GSC.

The generator with rotor short-circuited under a wind speed of $10 \mathrm{~m} / \mathrm{s}$ is tested and the rotor speed at the equivalent operating point is determined to be $1675 \mathrm{rpm}$. Then, the inverter is enabled and the rotor voltage is manipulated to operate the DFIG at unity power factor around synchronous speed (i.e. $1500 \mathrm{rpm}$ ). As shown in Fig. 18, the RSC supplies direct current to the rotor windings with the fact that one phase current is two times the current of each of the other two phasecurrents, causing unbalanced heating in IGBTs. By increasing the frequency of rotor currents with the phase sequence opposite to the rotor rotating direction, the rotor speed increases. As this process is manually controlled, fluctuations in rotor and stator currents as well as mechanical torque can be observed in Fig. 18 and 19. The transition from DFIG mode to IG mode takes place after the rotor speed reaches the speed determined in the first step, the crowbar is enabled while RSC is disconnected. The rotor speed and torque waveforms demonstrate that smooth transition from DFIG mode to IG mode is achieved. It can be seen that the rotor current decreases while stator current increases under IG mode because reactive current is supplied by the RSC in DFIG mode whereas the grid provides reactive power for the generator excitation under IG mode (GSC is not available to provide reactive power support in this test.). Since the inverter control unit maintains the original control signal (which acts similarly to the RSC controller tracing the mechanical torque reference during IG mode as discussed in Section VI-B), the system transits from IG mode back to DFIG mode by connecting RSC to the rotor and disabling the crowbar. The transition is also smooth without any abrupt variation in rotor speed and torque as shown in Fig. 18 and 19 respectively. Therefore, the test results validated the basic concept of the multimode operation.

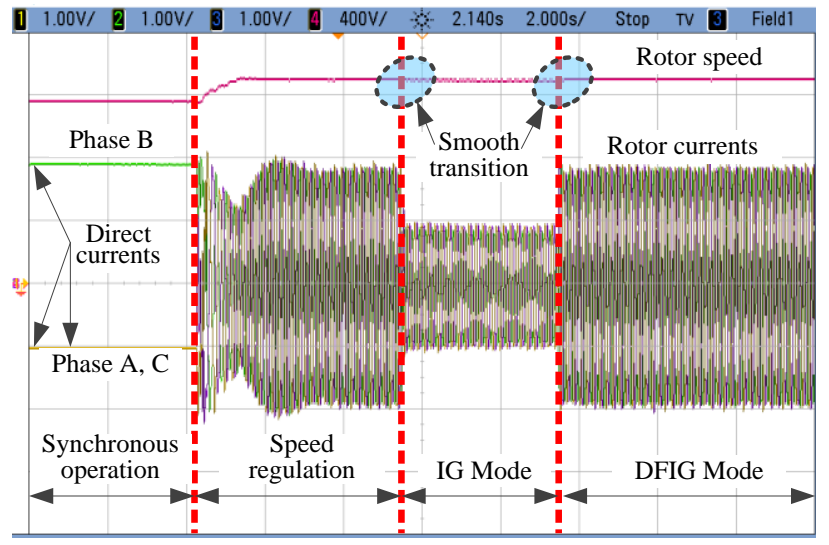

Fig. 18 Test results showing rotor speed and rotor currents. 


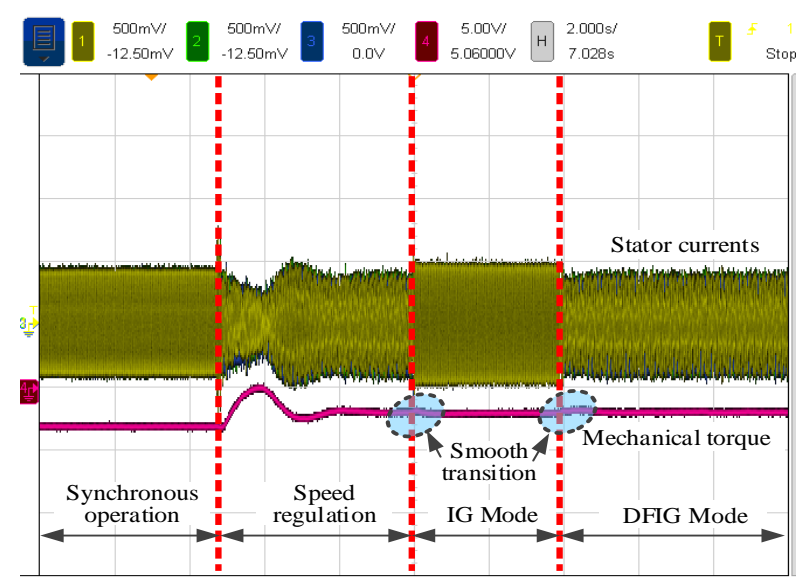

Fig. 19 Test results showing mechanical torque and stator currents.

\section{CONCLUSION}

In this paper, a multimode operation control strategy is implemented to prevent the DFIG operating around the synchronous speed. Hence, large junction temperature variation in the semiconductor devices due to low slip frequency can be avoided. Supplementary control strategies are proposed to minimize the transients caused by the mode transitions. Detailed simulations are carried out to investigate the performance of the proposed control strategy in a remote area power supply system. Power loss and thermal network for the RSC is established to verify the effectiveness of the proposed strategy. The results validate that the deadband set for synchronous operation can reduce high temperature variations. Sensitivity analysis shows that the DFIG can ride-through the deadband to avoid unnecessary mode transitions if DFIG is confronted with highly variable wind speed and passes through synchronous speed. The proposed strategy does not require any additional hardware and modifications to the current system configuration while the grid-code standards can be satisfied. The concept of multimode operation has also been verified using an experimental setup. Furthermore, when the DFIG operating in induction generator mode, it can also enhance the frequency support with natural inertial response using its stored kinetic energy without any control intervention, which can be further explored.

\section{APPENDIX}

TABLE I

DFIG PARAMETERS

\begin{tabular}{llcl}
\hline \hline \multicolumn{1}{c}{ Parameter } & Value & Parameter & Value \\
\hline Rated power & $1.5 \mathrm{MW}$ & $\boldsymbol{L}_{\boldsymbol{m}}$ & 2.9 p.u. \\
Turbine inertia constant & $4.32 \mathrm{~s}$ & $\boldsymbol{R}_{\boldsymbol{s}}$ & 0.023 p.u. \\
Rated wind speed & $11 \mathrm{~m} / \mathrm{s}$ & $\boldsymbol{L}_{\boldsymbol{s}}$ & $0.18 \mathrm{p} . u$. \\
Rated stator voltage & $400 \mathrm{~V}$ & $\boldsymbol{R}_{\boldsymbol{r}}$ & $0.016 \mathrm{p} . \mathrm{u}$. \\
Rated DC bus voltage & $800 \mathrm{~V}$ & $\boldsymbol{L}_{\boldsymbol{r}}$ & 0.16 p.u. \\
Crowbar resistance & $0.2 \Omega$ & $\boldsymbol{\omega}_{\mathrm{l}}$ & 1.08 p.u. \\
$\boldsymbol{f}_{\mathrm{sw}}$ & $1350 \mathrm{~Hz}$ & $\boldsymbol{\omega}_{\mathrm{h}}$ & 1.11 p.u. \\
\hline \hline
\end{tabular}

\section{REFERENCES}

[1] S. Yang, A. Bryant, P. Mawby, D. Xiang, L. Ran, and P. Tavner, "An industry-based survey of reliability in power electronic converters," IEEE Trans. Ind. Appl., vol. 47, no. 3, pp. 1441-1451, 2011.

[2] J. Ribrant and L. M. Bertling, "Survey of failures in wind power systems with focus on swedish wind power plants during 1997-2005," IEEE Trans. Energy Convers., vol. 22, no. 1, pp. 167-173, 2007.

[3] D. Zhou, F. Blaabjerg, M. Lau, and M. Tonnes, "Thermal behavior optimization in multi-mw wind power converter by reactive power circulation," IEEE Trans. Ind. Appl., vol. 50, no. 1, pp. 433-440, 2014.

[4] S. Yang, D. Xiang, A. Bryant, P. Mawby, L. Ran, and P. Tavner, "Condition monitoring for device reliability in power electronic converters: A review," IEEE Trans. Power Electron., vol. 25, no. 11, pp. 2734-2752, 2010.

[5] A. Wintrich, U. Nicolai, W. Tursky, and T. Reimann, "Application manual power semiconductors," S. I. GmbH, Ed., 2nd ed. Nuremberg, Germany: ISLE Verlag, 2015.

[6] T. Lei, M. Barnes, and A. C. Smith, "Thermal cycling evaluation for DFIG wind turbine power converter based on joint modelling," in Proc. Energy Conversion Congress and Exposition (ECCE), 2013 IEEE, 2013, pp. 3845-3851.

[7] M. Z. Sujod, I. Erlich, and S. Engelhardt, "Improving the reactive power capability of the DFIG -based wind turbine during operation around the synchronous speed," IEEE Trans. Energy Convers., vol. 28, no. 3, pp. 736-745, 2013.

[8] L. Wei, R. J. Kerkman, R. A. Lukaszewski, H. Lu, and Z. Yuan, "Analysis of IGBT power cycling capabilities used in doubly fed induction generator wind power system," IEEE Trans. Ind. Appl., vol. 47, no. 4, pp. 1794-1801, 2011.

[9] D. Zhou, F. Blaabjerg, M. Lau, and M. Tonnes, "Thermal cycling overview of multi-megawatt two-level wind power converter at full grid code operation," IEEJ Journal of Industry Applications, vol. 2, no. 4, pp. 173-182, 2013.

[10] S. Engelhardt, I. Erlich, C. Feltes, J. Kretschmann, and F. Shewarega, "Reactive power capability of wind turbines based on doubly fed induction generators," IEEE Trans. Energy Convers., vol. 26, no. 1, pp. 364-372, 2011.

[11] J. Jung and W. Hofmann, "Investigation of thermal stress in the rotor of doubly-fed induction generators at synchronous operating point," in Proc. Electric Machines \& Drives Conference (IEMDC), 2011 IEEE International, 2011, pp. 896-901.

[12] M. Z. Sujod and I. Erlich, "Reactive power capability of DFIG based wind turbine around synchronous operating point with two-level and three-level npc converter," in Proc. PowerTech (POWERTECH), 2013 IEEE Grenoble, 2013, pp. 1-6.

[13] L. Wei, J. McGuire, and R. A. Lukaszewski, "Analysis of PWM frequency control to improve the lifetime of pwm inverter," IEEE Trans. Ind. Appl., vol. 47, no. 2, pp. 922-929, 2011.

[14] T. Lei, M. Barnes, S. Smith, H. Sung-ho, A. Stock, and W. E. Leithead, "Using improved power electronics modeling and turbine control to improve wind turbine reliability," IEEE Trans. Energy Convers., vol. 30, no. 3, pp. 1043-1051, 2015.

[15] R. Pena, J. C. Clare, and G. M. Asher, "Doubly fed induction generator using back-to-back PWM converters and its application to variablespeed wind-energy generation," Electric Power Applications, IEE Proceedings -, vol. 143, no. 3, pp. 231-241, 1996.

[16] G. Abad, Doubly fed induction machine : Modeling and control for wind energy generation applications: Hoboken, NJ : IEEE Press, c2011., 2011.

[17] SEMIKRON. SKiiP 2013 GB172-4DW V3 [Online]. Available: https://www.semikron.com/products/product-classes/ipm/detail/skiip2013-gb172-4dw-v3-20451248.html

[18] M. Bartram, J. v. Bloh, and R. W. D. Doncker, "Doubly-fed-machines in wind-turbine systems: Is this application limiting the lifetime of igbtfrequency-converters?," in Proc. Power Electronics Specialists Conference, 2004. PESC 04. 2004 IEEE 35th Annual, 2004, pp. 25832587.

[19] Y. Tan, L. Meegahapola, and K. M. Muttaqi, "A suboptimal powerpoint-tracking-based primary frequency response strategy for DFIGs in hybrid remote area power supply systems," IEEE Trans. Energy Convers., vol. 31, no. 1, pp. 93-105, 2016.

[20] L. G. Meegahapola, T. Littler, and D. Flynn, "Decoupled-DFIG fault ride-through strategy for enhanced stability performance during grid faults," IEEE Trans. Sustain. Energy, vol. 1, no. 3, pp. 152-162, 2010. 
[21] A. Etxegarai, P. Eguia, E. Torres, A. Iturregi, and V. Valverde, "Review of grid connection requirements for generation assets in weak power grids," Renew. Sustain. Energy Rev., vol. 41, pp. 1501-1514, 2015.

[22] A. K. Pathak, M. P. Sharma, and M. Bundele, "A critical review of voltage and reactive power management of wind farms," Renew. Sustain. Energy Rev., vol. 51, pp. 460-471, 2015.

[23] Fulintech Science \& Technology Co.,Ltd. Resistors for wind energy catalog [Online]. Available: http://www.flt-resistor.com/productcnplc77.html.

[24] G. Lalor, A. Mullane, and M. O'Malley, "Frequency control and wind turbine technologies," IEEE Trans. Power Syst., vol. 20, no. 4, pp. $1905-$ 1913, 2005.

[25] Festo Didactic Ltée/Ltd. "Principles of doubly-fed induction generators (DFIG): Courseware sample" [Online]. Available: https://www.labvolt.com/downloads/86376_f0.pdf

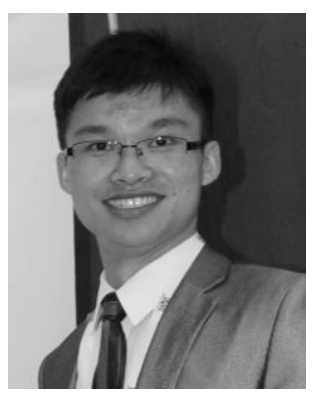

Yingjie Tan (S'12) received the B.Sc. (Eng.) (Hons.) degree in electrical engineering and automation from the China University of Petroleum (Huadong), Qingdao, China, in 2012. He is currently working toward the Ph.D. degree at the University of Wollongong, Wollongong, Australia.

His research interests are renewable distributed generation and microgrids.

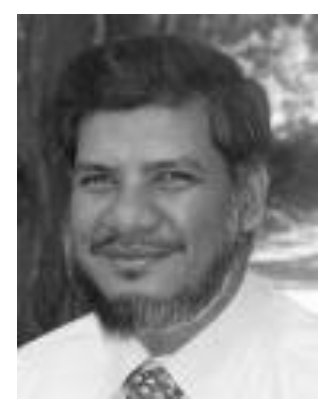

Kashem M. Muttaqi (M'01-SM'05) received the B.Sc. degree in electrical and electronic engineering from the Bangladesh University of Engineering and Technology, Dhaka, Bangladesh, in 1993; the M.Eng.Sc. degree in electrical engineering from the University of Malaya, Kuala Lumpur, Malaysia, in 1996; and the $\mathrm{Ph} . \mathrm{D}$. degree in electrical engineering from Multimedia University, Selangor, Malaysia, in 2001.

He is currently a Professor with the School of Electrical, Computer, and Telecommunications Engineering, and a Member of Australian Power Quality and Reliability, University of Wollongong, Wollongong, Australia. He was associated with the University of Tasmania, Australia, as a Research Fellow/Lecturer/Senior Lecturer from 2002 to 2007, and with the Queensland University of Technology, Australia, as a Research Fellow from 2000 to 2002. Previously, he also worked for Multimedia University, as a Lecturer for three years. He has more than 18 years of academic experience, and is author or coauthor of more than 200 papers in international journals and conference proceedings. His research interests include distributed generation, renewable energy, electrical vehicles, smart-grid, power system planning, and control.

Dr.Muttaqi is an Associate Editor of the IEEE TRANSACTIONS ON INDUSTRY APPLICATIONS.

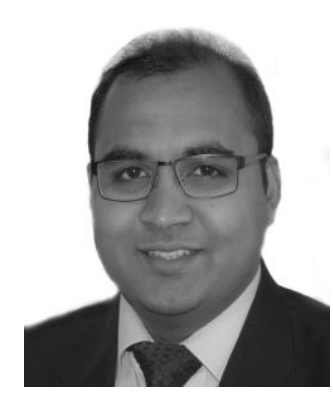

Lasantha Meegahapola (S'06-M'11) received his BSc. Eng. degree in Electrical Engineering (First Class) from the University of Moratuwa, Sri Lanka in 2006, and his PhD degree from Queen's University of Belfast, UK in 2010. His doctoral study was based on the investigation of power system stability issues with high wind penetration, and research was conducted in collaboration with EirGrid (Republic of Ireland-TSO). In addition, he conducted extensive research studies on coordinated reactive power dispatch during steady-state and dynamic/transient conditions for networks with high wind penetration. He was a visiting researcher in the Electricity Research Centre, University College Dublin, Ireland (2009/2010). From 2011-2014 he was employed as a lecturer at the University of Wollongong (UOW) and continues as an honorary fellow at UOW. He is currently employed as a lecturer at Royal Melbourne Institute of Technology. He is a member of IEEE and IEEE Power Engineering Society (PES).

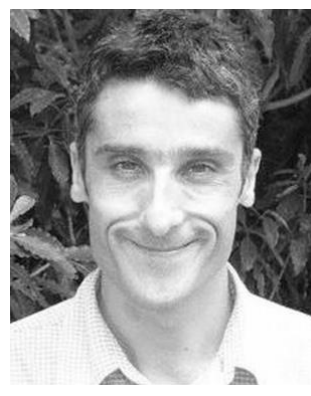

Phil Ciufo (SM'07) received the B.E. (Hons.) and M.E. (Hons.) degrees in electrical engineering from the University of Wollongong, Wollongong, Australia, in 1990 and 1993, respectively, and the Ph.D. degree in electrical engineering in 2002.

Dr. Ciufo has had various stints in industry as an Electrical Engineer and returned to academia in 2007. Currently, he is an Associate Professor with the University of Wollongong. His research interests include modeling and analysis of power distribution systems, distribution automation, modeling and analysis of ac machines, power system harmonics, and power system reliability. 